http://doi.org/10.15359/ree.13-1.9

\title{
Proyecto: educación en línea
}

\author{
Ligia María Angulo Hernández ${ }^{1}$ \\ Académica de la División de Educación Rural de la Universidad Nacional \\ Heredia, Costa Rica
}

Recibido 6 de noviembre de 2007 - Aprobado 15 de abril de 2008

Resumen. Se presenta de manera concisa, una propuesta de aplicación real sobre los criterios y los elementos básicos para elaborar, desde los centros de formación superior proyectos de educación en línea. Ofrece al lector una guía en la modalidad de resumen ejecutivo, explicando los principales aspectos en la realización del proyecto, desde el planteamiento hasta su revisión final. Considera los aportes de cada uno de los especialistas involucrados en este proceso: expertos en conocimiento, diseñadores gráficos, programadores de sistemas y líderes organizadores.

Palabras clave. Proyecto educativo, educación en línea, tecnología de la información y la comunicación, diseñador gráfico, programador de sistemas, experto en conocimiento.

Abstract. This is a presentation of a proposal for authentic application of the basic criteria and elements to create projects related to on line education in Centers of Superior Education. It provides a guide in a useful summary format, which explains the main aspects in the creation of the project from the planning stage to the final stage supervision. It is supported by a range of specialists who were involved in the process including experts in knowledge, graphic design, system programmers, and organizational leaders.

Key words. Educational project, online educational, information and communication technology, graphic design, system programmers, experts in knowledge.

"Sólo aquellos que se arriesgan a ir muy lejos, pueden llegar a saber lo lejos que pueden ir".

T. S. Elliot

\section{INTRODUCCIÓN}

Las experiencias adquiridas a partir de la participación en los últimos años en distintos talleres, foros, videoconferencias y cursos en línea, tanto en el ámbito nacional como en el internacional, sobre la temática del uso de las herramientas de la información y la comunicación, me ha motivado para compartir con estudiantes, investigadores, asesores y docentes algunos de los lineamientos

\footnotetext{
Máster en Docencia, Licenciada en Ciencias de la Educación con énfasis en I y II ciclos. Experiencia en Educación Primaria e Informática Educativa. Coautora de investigaciones y artículos educativos. Actualmente, es académica e investigadora y coordina el Proyecto Red Regional de Educación Rural de la División de Educación Rural de la Universidad Nacional. Correo electrónico: anguloligia@hotmail.com
} 
generales para desarrollar proyectos educativos en el campo de la educación superior a distancia. Consciente del interés de las instituciones por ofrecer, en la actualidad, una enseñanza de calidad, basada en el conocimiento de la era de la información, se plantean un reto como facilitadores en la formación de las competencias y las habilidades que requieren los estudiantes y los académicos, en relación con el uso educativo de las tecnologías.

Las nuevas posibilidades que permiten la incorporación y la utilización de los recursos tecnológicos a los procesos de enseñanza y de aprendizaje, sorprenden, día con día, en sus distintas aplicaciones en los procesos de enseñanza y de aprendizaje, y nos invitan a reflexionar sobre los desafíos de la universidad en el siglo XXI. Para Miratía (2001), en esta época se debe considerar la aplicación de la informática, la computación y el desarrollo de las telecomunicaciones como herramientas para la sistematización y la construcción del conocimiento y el aprendizaje de los alumnos, las que, al ser integradas en los programas educativos, posibilitan su uso pedagógico y potencian la experiencia, la innovación y la capacidad académica de la institución.

Actualmente, el concepto universidad virtual no nos es ajeno como sí lo fue hace algunos años; éste responde al paradigma cognitivo, el cual se fundamenta en los aportes de la psicología y de la ciencia cognitiva sobre el cómo aprende el ser humano, y nos conduce a reconocer que el estudiante no sólo adquiere información, sino que también debe aprender estrategias cognitivas, es decir, procedimentales para adquirir, recuperar y usar la información. Este paradigma implica un concepto educativo global, en el que el espacio físico y la necesidad de sincronismo desaparecen, y se hace necesario convertir en compañeros y compañeras a todos los estudiantes que se encuentran separados por una distancia considerable. Éstos deben aprender a intercambiar, a colaborar, a cooperar y a compartir con los demás, sin la ¿necesidad?, o la ¿posibilidad?, de tener algún tipo de contacto desde el punto de vista físico. Por tanto, la educación a distancia no significa una educación distanciada ${ }^{2}$.

Los aportes de la tecnología de la información y la comunicación han enriquecido los procesos de enseñanza y de aprendizaje, y deben ser vistas como herramientas de apoyo. Éstas permiten el acceso a la educación a todas las personas interesadas y que, tradicionalmente, no se les atendía por encontrarse en zonas lejanas a instituciones formadoras. Además, se diversifican las opciones para facilitar el estudio a grupos cada vez más heterogéneos, tanto en orígenes y composición como en trayectorias y propósitos.

Los proyectos educativos en línea permiten entre otras ventajas, ofrecer un nuevo modo de relación con los demás, en el que el estudiante o usuario es autónomo e independiente, pero que, a la vez, potencia la interacción desde la virtualidad. Esto significa que la formación de profesionales en las universidades debe responder a los requerimientos actuales, por ejemplo: que el perfil profesional no sea definido como un especialista en el ejercicio de una disciplina, sino como un especialista con las capacidades necesarias para acceder, interpretar y aplicar conocimiento en varias disciplinas. Por esta razón, los centros de enseñanza requieren que los programas, los proyectos y los diseños curriculares que se ofrecen posean, como una de sus características, la flexibilidad.

El plantear un proyecto educativo apoyado en las nuevas tecnologías de la información y la comunicación, nos proporciona un espacio para reinterpretar y repensar la educación desde su enfoque, metodología, didáctica, evaluación, tipo de comunicación, características de los estudiantes, académicos, entre otros elementos. Un proyecto en el que la relación entre el que aprende y la computadora persigue un objetivo de carácter formativo, y cuya construcción de conocimientos incluye la discusión, la reflexión y la toma de decisiones en la resolución de problemas. Todo proyecto que se plantee debe buscar el desarrollo de habilidades tanto individuales como grupales, y su éxito va

Frase expuesta por el señor Carlos Tünnermann Bernheim en la conferencia inaugural "Los desafíos de la Universidad en el siglo XXI", curso lectivo 2007. Centro de Investigación y Docencia en Educación (CIDE), de la Universidad Nacional de Costa Rica. 
a depender, principalmente, de la interacción, la elaboración de los materiales y la forma en que el facilitador se involucre en el proceso de interacción y maneje sus materiales.

La educación en línea es una propuesta de formación pedagógica emergente, en la que muchos nos iniciamos, con expectativas y temores, por descubrir algo diferente.

\section{CRITERIOS PARA ELABORAR PROYECTOS EDUCATIVOS EN LÍNEA}

Para desarrollar proyectos de educación en línea, Bates (2000) propone una serie de criterios que orientan las decisiones bajo un modelo que denominó ACTIONS ${ }^{3}$. El planteamiento de Bates, invita a todos los facilitadores de la educación en línea a responder un conjunto de preguntas en el momento en que seleccionan recursos y medios tecnológicos específicos para un proyecto o curso. El autor agrega que las respuestas que se puedan dar variarán, según el contexto específico de los interesados donde se aplique. A las diferencias entre un proyecto u otro, el autor las denomina necesidades de aprendizajes cambiantes, y la aplicación de las nuevas tecnologías de la información y la comunicación, se dan según las necesidades reales de los usuarios y el tipo de mediación tecnológica por utilizar, en un curso o proyecto. El modelo ACTIONS es ideal para aplicar en la toma de decisiones, en la modalidad de educación en línea. Para Bates, el éxito del uso de la tecnología en la educación y en el aprendizaje depende de la capacidad de introducir cambios en la cultura de las personas, en la forma de aprender y en las estructuras organizativas.

Los criterios se componen de siete elementos cuyas iniciales forman el término inglés ACTIONS, los cuales se detallan, en forma general, a continuación:

Tabla $\mathrm{N}^{\mathrm{o}} 1$

\section{El modelo ACTIONS}

\begin{tabular}{|l|l|}
\hline \multicolumn{1}{|c|}{ Parámetros } & \multicolumn{1}{c|}{ Descripción } \\
\hline $\begin{array}{l}\text { Access } \\
\text { (acceso) }\end{array}$ & $\begin{array}{l}\text { Responde a la pregunta ¿qué tan accesible y flexible debe ser la tecnología para los } \\
\text { estudiantes? }\end{array}$ \\
\hline $\begin{array}{l}\text { Cost structure } \\
\text { (estructura de costos) }\end{array}$ & $\begin{array}{l}\text { Estructura de costos para cada tecnología y el costo unitario por participante en el } \\
\text { programa. Analizar los costos de inversión, operación, para el emisor, para el receptor } \\
\text { y para producir materiales, de acuerdo con la tecnología elegida. }\end{array}$ \\
\hline $\begin{array}{l}\text { Teaching and learning } \\
\text { (enseñanza y aprendizaje) }\end{array}$ & $\begin{array}{l}\text { La flexibilidad en los medios dependerá del tipo de contenido por desarrollar, de las } \\
\text { habilidades de los maestros y los estudiantes para aprovechar esos medios, y desarrollar } \\
\text { habilidades de análisis y evaluación. }\end{array}$ \\
\hline $\begin{array}{l}\text { Interactivity and user friendliness } \\
\text { (interactividad y facilidad de uso) }\end{array}$ & $\begin{array}{l}\text { Se debe tener claro qué tipo de interacción permite la tecnología elegida y qué tan fácil } \\
\text { es de usar. }\end{array}$ \\
\hline $\begin{array}{l}\text { Organization } \\
\text { (organización) }\end{array}$ & $\begin{array}{l}\text { Necesidad de un coordinador general de proyectos, un equipo interdisciplinario de especia- } \\
\text { listas, relacionar las temáticas, cursos y asignar los tutores por temáticas. } \\
\text { Organización y formación del personal encargado en el proyecto. }\end{array}$ \\
\hline $\begin{array}{l}\text { Novelty } \\
\text { (novedad) }\end{array}$ & $\begin{array}{l}\text { Respuesta a la pregunta ¿qué tan novedosa es la tecnología que vamos a utilizar?,y la relación } \\
\text { con las expectativas, modas, mercadotecnia en la demanda por lo nuevo. }\end{array}$ \\
\hline $\begin{array}{l}\text { Speed of development } \\
\text { (velocidad de desarrollo) }\end{array}$ & $\begin{array}{l}\text { Los contenidos y las temáticas por tratar deben actualizarse, lo más frecuentemente } \\
\text { posible, a causa de su rápida desactualización. }\end{array}$ \\
\hline
\end{tabular}

Nota. Elaboración personal con base en el modelo que propone Bates (2000), como experto en el uso de las tecnologías en la educación a distancia.

La propuesta se basa en su experiencia como director y catedrático ejecutivo de investigación, planeación estratégica e información tecnológica, por más de treinta años en Columbia Británica, Canadá. Además, de diversos estudios de casos para mejorar las gestiones del cambio y uso de la tecnología y motivación del profesorado. 


\section{INVENTARIO DE RECURSOS Y MEDIOS: APLICACIÓN EDUCATIVA}

Un proyecto educativo apoyado en el uso y aplicación de las tecnologías de la información y la comunicación (TICs), en su proceso de formulación, requiere enlistar aquellos recursos con los que cuenta la Institución que lo patrocina y detallar cuál será la aplicación educativa que tendrá el recurso tecnológico en el proyecto educativo ${ }^{4}$.

A continuación, se ejemplifican algunos de estos recursos, sin pretender mostrar un producto acabado de ellos, ya que, en esta oportunidad, se dejan de lado algunos comentarios, tales como las ventajas y las desventajas de cada uno de ellos. Es importante seleccionar aquellos medios de comunicación que estén acordes con el desarrollo de los objetivos propuestos en el proyecto.

Tabla $\mathrm{N}^{\mathrm{o}} 2$

\section{Educación en línea}

\begin{tabular}{|c|c|}
\hline Medios & Aplicación educativa al proyecto \\
\hline $\begin{array}{l}\text { Internet. Red de redes mundial de equipos infor- } \\
\text { máticos que se comunican mediante ordenadores. } \\
\text { Funciona como una gran "biblioteca mundial" que } \\
\text { permite la consulta de cualquier documento que } \\
\text { esté disponible en algún servidor en el planeta. }\end{array}$ & $\begin{array}{l}\text { Posibilidad de intercambiar documentos (audio-escrito-visual) } \\
\text { con otras personas que se encuentran conectadas al sistema. } \\
\text { Útil para cualquier modalidad educativa: presencial, abierta, } \\
\text { continua, en línea. } \\
\text { Útil para cualquier nivel educativo: primaria, secundaria, } \\
\text { licenciatura o postgrado. } \\
\text { Para cualquier persona con necesidades educativas: amas de } \\
\text { casa, obreros, discapacitados, privados de libertad, otros. }\end{array}$ \\
\hline $\begin{array}{l}\text { Videoconferencia. Comunicación multilateral y } \\
\text { sincrónica de imagen, sonido y datos, entre dos o } \\
\text { más puntos. } \\
\text { Existen dos tipos: la grupal y la de escritorio. }\end{array}$ & $\begin{array}{l}\text { Etapas de preparación. Planteamiento de las ideas, organiza- } \\
\text { ción del contenido, definición del receptor, selección de exper- } \\
\text { tos y planeación de evaluación. } \\
\text { Útil para las modalidades curriculares de curso, talleres y } \\
\text { seminarios. } \\
\text { Un ejemplo de una estructura de trasmisión es considerar los } \\
\text { siguientes elementos: la presentación en la que se identifica } \\
\text { la sede y el título del trabajo, el desarrollo de las técnicas de } \\
\text { enseñanza y las actividades, las preguntas o los comentarios y, } \\
\text { como último apartado, la síntesis y las conclusiones, en las que } \\
\text { se resume lo expuesto. }\end{array}$ \\
\hline $\begin{array}{l}\text { Multimedios. Integración de varios elementos en, } \\
\text { alguna actividad o material, por ejemplo, una } \\
\text { presentación, tales como: texto e información } \\
\text { en forma de párrafos, animación, imágenes con } \\
\text { movimientos, vídeo, imágenes, grabaciones de } \\
\text { eventos, gráficos, imágenes de objetos, personas o } \\
\text { sitios, audio, sonidos digitalizados y almacenados, } \\
\text { entre otros. } \\
\text { Los elementos deben ser utilizados de forma } \\
\text { creativa y poseer la capacidad de interactividad } \\
\text { para que resulten significativos en el proceso de } \\
\text { aprendizaje. }\end{array}$ & $\begin{array}{l}\text { Se elabora con el apoyo de distintos especialistas para cumplir } \\
\text { el objetivo educativo. } \\
\text { Participan los programadores e ingenieros en computación, } \\
\text { especialistas en educación, diseñadores de interfaz o gráficos, } \\
\text { así como los autores o guionistas encargados de la edición y } \\
\text { del procesamiento de la información en la computadora. }\end{array}$ \\
\hline
\end{tabular}

Continúa...

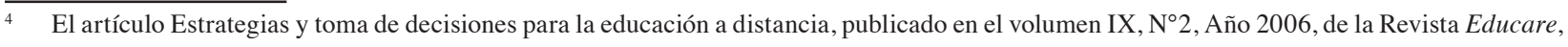
detalla sobre algunos de los recursos tecnológicos aplicables en la educación. 


\begin{tabular}{|c|}
\hline Medios \\
\hline $\begin{array}{l}\text { Televisión educativa. Sistema de emisión y re- } \\
\text { cepción a distancia de imágenes en movimiento y } \\
\text { sonidos sincronizados, a través de ondas electro- } \\
\text { magnéticas. }\end{array}$ \\
\hline $\begin{array}{l}\text { Vídeo. Medio para almacenar imagen, sonido y } \\
\text { movimiento, Pueden ser reproducidos cuantas } \\
\text { veces se desee. Si se manipulan con creatividad se } \\
\text { pueden lograr programas de mayor calidad y pre- } \\
\text { cisión que los que produce la televisión en directo. }\end{array}$ \\
\hline $\begin{array}{l}\text { Audioconferencia. Enlace entre varios participan- } \\
\text { tes o grupos de participantes, por teléfono o algún } \\
\text { programa computacional, usado con esa finalidad, } \\
\text { de manera que puedan realizar un encuentro a } \\
\text { distancia. }\end{array}$ \\
\hline
\end{tabular}

Materiales virtuales. Éstos pueden ser creados o utilizar aquellos que se encuentran disponibles en la Web.

Es importante considerar los permisos de autoría correspondientes, aun si éstos se encuentran en Internet.

Correo electrónico. Intercambio de mensajes entre personas conectadas a un computador que tiene conexión a la Internet.

Listas de distribución. Llamados foros de discusión. Permite ver las participaciones de los involucrados con mensajes ordenados por temáticas y respuestas, según las intervenciones.

Las personas son registradas e identificadas, previamente, en dicha lista por medio de un login de su dirección electrónica.

Chat. Sistema de comunicación sincrónica en internet tipo talk on line, con el que los usuarios se pueden conectar entre sí.

Web blogs. Sistema que funciona como una bitácora; en él se escriben artículos que pueden ser comentados por cualquier persona en Internet.

Los comentarios son presentados en forma cronológica inversa (el último aparece de primero), lo que facilita la forma de lectura.
Aplicación educativa al proyecto

Distribuyen los contenidos educativos a un usuario o a un grupo (pequeño o grande) de usuarios ubicados lejos del facilitador. Se pone a disposición del educador para acercar, explicar, mostrar, fenómenos o actos de estudio y lograr un proceso de aprendizaje.

La televisión es uno de los medios idóneos para sitios lejanos, donde se reúnen los alumnos para recibir la señal, mediante una antena y un monitor de televisión.

Los vídeos contienen dosis de auto-didactismo e independencia. El estudiante no necesita reunirse en aulas, sino sólo activar un medio electrónico que le permita ver y escuchar en su casa o escritorio.

Usos educativos.Entrevistas, evaluaciones, ampliación de temas, estudios de casos, solución de problemas y socialización.

Se pueden elaborar síntesis tipo comentario que pasarán a ser de autoría propia o de la institución que lo desarrolle, recurrir a documentación física (guías didácticas, antologías, textos de autoestudio, apuntes, u otros) o virtual, tales como las presentaciones en Power Point, materiales en vídeo y en audio.

Envío y recepción de mensajes u otros documentos adjuntos, tales como: artículos, tareas, ejercicios u otros. Permite realizar aclaraciones sobre el tema en cuestión o acciones futuras, de una manera más rápida y con mayor cobertura.

Se establece contacto con personas de diferentes ámbitos geográficos para intercambiar ideas, informaciones, experiencias, trabajos, actualizar información sobre algún tema en común, solicitar asesoría u orientación, discutir casos, diagnósticos, tratamiento de soluciones, entre otros.

Posibilidad de realizar actividades conjuntas, discusiones colectivas, realizar preguntas al grupo de trabajo, socializar entre los alumnos.

Son llamados edublogs cuando son usados en educación como apoyo a las metodologías constructivistas y enfoques colaborativos, debido a que estudiantes y educadores pueden participar en una misma bitácora.

Una de las características de este recurso es que los participantes juegan un rol activo y emiten comentarios o añaden nuevos datos a la información.

Nota: Elaboración personal con base en la lectura de documentos varios alusivos a la temática de los recursos digitales. 


\section{GUÍA PARA DEFINIR UN PROYECTO EDUCATIVO}

Lo que voy a presentar no es la única metodología para desarrollar proyectos que existe, sino que cada proyecto establece la propia, dependiendo de los objetivos y las características que posee el trabajo. A partir de estas características, se deriva una fórmula básica aplicable a cualquier proyecto educativo:

$$
\mathbf{M}=\mathbf{f}(\mathbf{O}, \mathbf{C})
$$

La $\mathbf{M}=$ metodología, se encuentra en relación directa con $\mathbf{f}=$ función, en proporciones iguales de tanto los $\mathbf{O}=$ objetivos como de las $\mathbf{C}=$ características particulares del proyecto, en nuestro caso, un proyecto de educación en línea.

Con base en esa función, algunos de los principales aspectos que debemos considerar para elaborar un proyecto de educación en línea, se exponen a continuación, en la modalidad de resumen ejecutivo.

\section{a. Nombre del proyecto educativo}

Que sea conciso y descriptivo, de manera que aclare su contenido y haga referencia a las temáticas del módulo, curso, taller, entre otros que se pretende desarrollar.

\section{b. Planteamiento del problema}

Mencionar los antecedentes del proyecto, o el surgimiento de la idea original. De no ser así, se detalla el problema existente en búsqueda de soluciones.

\section{c. Propósitos}

Expresar, con una idea, el fin que se piensa alcanzar con el proyecto. Debe responder a varias interrogantes, tales como: qué, quién, cómo, cuándo y otras. Además, aclarar las intenciones que busca la institución que respalda el programa.

\section{d. Objetivos}

Detallar, con una idea, el fin que se piensa alcanzar con el proyecto, desde el punto de vista del participante. El objetivo expresa lo que se busca para el estudiante. 


\section{e. Justificación}

Indicar el porqué se debe desarrollar el proyecto, su necesidad, el cómo quedaría satisfecha tal necesidad y el porqué ese proyecto es importante.

\section{f. Alcance}

Indicar en qué forma impacta el proyecto, ya sea al interior de la institución, al exterior o en otros ámbitos.

\section{g. Metas}

Las metas son una variante del objetivo. Una meta es un objetivo cuantificable que indica cantidades, fechas y porcentajes en la mayoría de los casos.

\section{h. Características}

Es el bosquejo del proyecto, se define si el proyecto es un curso, un taller, un programa de diplomado u otro. Se indica, en este apartado, la duración estimada, el público al que va dirigido, las herramientas por emplear, la estructura temática, los requisitos académicos y técnicos, los informes u otro documento que aclare su particularidad.

\section{i. Ventajas}

Expresar, claramente, los beneficios y las características positivas del proyecto, sus ganancias o conveniencias, sus valores diferenciales frente a otras alternativas, tanto desde el punto de vista de la institución que ofrecerá el programa, como desde el punto de vista del alumno que tomará dicho programa.

\section{j. Estrategias de desarrollo}

Las estrategias son las directrices empleadas en el desarrollo del proyecto. Una de las estrategias más común es: diseño, desarrollo y evaluación en forma repetitiva hasta alcanzar el objetivo. Aquí se indica la dinámica por seguir en la creación del programa.

Este ejemplo mostrado es un posible bosquejo para elaborar un proyecto educativo, no omitimos que este modelo de resumen no es perfecto, ni es el único; pero sí propone una serie de elementos considerados relevantes, cuya definición puede lograr que el proyecto sea efectivo en su aplicación. 


\section{REQUERIMIENTOS BÁSICOS PARA EL DESARROLLO DEL PROYECTO}

Para desarrollar un proyecto educativo apoyado en la tecnología, se hace necesario contar con varios requerimientos: los recursos humanos, los recursos tecnológicos, los recursos de apoyo administrativo y técnico, el contar con presupuesto, el acceso a una plataforma tecnológica (software o paquete integrado por módulos con funcionalidades independientes que incluye la logística necesaria para ofrecer la asistencia técnica) y la infraestructura adecuada, por mencionar algunos de ellos. Se detallan algunas de las funciones del recurso humano, el cual considero es el recurso primordial de cualquier proyecto educativo.

Entre los integrantes del equipo interdisciplinario se debe contar con los siguientes:

a. Experto en conocimiento. Llamado guía, tutor o colaborador. Apoya brindando el contenido recurriendo a su experiencia o distintas fuentes de información. Es el especialista en el tema. Profesional que domina las estructuras curriculares del nivel en el que opera.

b. Diseñador instruccional. Experto en estrategias de aprendizaje con una visión amplia e integral. En la mayoría de los casos, es un psicólogo o pedagogo. Su función es la de seleccionar, elaborar los ejercicios, los materiales y las evaluaciones, acordes con los contenidos dados por el experto en el conocimiento. Diseña el guión como se presentará el contenido.

c. Diseñador gráfico. Profesional en el área de la comunicación visual. Organiza la información en una estructura comunicativa visual que refuerza los objetivos y los contenidos de aprendizaje. Esto sin dejar de lado los aspectos estéticos de imagen, color, forma, fotografías y letras, todos ellos subordinados a la intención educativa del material.

El proceso que lleva a cabo un diseñador gráfico, en la educación en línea, consta de, al menos, cuatro etapas básicas que van de la mano con el resto del trabajo del equipo. En muchos casos, el aporte de este especialista se ve minimizado en el desarrollo de un proyecto. Debo indicar que la descripción de estas etapas no pretende convertirse en un manual de diseño para un proyecto de educación en línea, pues este trabajo le corresponde al especialista de comunicación visual.

- Definición del proyecto. Reconocimiento de los conceptos básicos, tales como: hacia quién va dirigido, cuáles son los objetivos que se persiguen, cómo se lleva a cabo la recopilación del material contenido textual y gráfico, qué definición se da de la estructura de navegación.

- Diseño de interfaz general. Por medio de un proceso creativo, se inicia la composición de formas, colores, fotografía y letras a partir de diferentes propuestas o bosquejos que definen e identifican, visualmente, el material.

- Desarrollo. Se plantean e integran todos los elementos visuales (estáticos y en movimiento) y textuales que conforman el proyecto.

- Revisión final. Se realiza, preferiblemente, con todo el equipo interdisciplinario para detectar fallas y proponer mejoras. Se pueden realizar pruebas con personas que reúnan las características de los usuarios finales. 
d. Programador de sistemas. Su función está enfocada, principalmente, a la publicación de programas educativos en línea y a garantizar, el correcto funcionamiento de los materiales creados y su uso en la plataforma y/o sistema seleccionado.

El programador es la persona encargada de armar y controlar la interfase y la aplicación al sistema. Trabaja con la información digital, hardware, software y redes. Da soporte y mantenimiento a proyectos o programas. Aplica algoritmos mediante un lenguaje de programación ejecutable en la computadora.

e. Líder organizador integrador: Es el responsable del equipo, coordina las tareas de diseño, desarrollo y evaluación del proyecto, planifica los tiempos, distribuye los recursos y los participantes, coordina las distintas áreas disciplinarias, es el encargado de las reuniones de equipo. Es llamado, por sus funciones, el administrador o coordinador de desarrollo.

Cada uno de los profesionales mencionados anteriormente, conforman el equipo interdisciplinario $^{5}$, el cual trabaja de forma conjunta en una misma infraestructura llamada Laboratorio de desarrollo. Éstos son centros de aplicaciones de software, y tienen como fin la investigación y el desarrollo de pruebas tecnológicas, a partir del desarrollo de proyectos innovadores en áreas específicas, mediante enfoques inter y multidisciplinarios. Algunos de los profesionales que laboran es estos espacios físicos son los ingenieros electrónicos y el personal de soporte técnico. El equipo interdisciplinario construye y desarrolla un mismo proyecto con un líder organizador integral. Este nuevo enfoque hace que el concepto, comúnmente, llamado laboratorio de cómputo no sea el idóneo para representar los roles de cada uno de los participantes descritos.

El proceso de elaboración de un proyecto de educación en línea, como por ejemplo, ofrecer un plan de estudios de formación de maestros rurales en los ámbitos nacional e internacional (en opciones de grado y pregrado), puede tener una duración aproximada de tres meses o más, tiempo estimado desde la creación de la idea hasta su ejecución e inclusión del plan de estudios en una plataforma tecnológica. Un proyecto como el anterior debe ser piloteado, al menos, de dos o tres veces antes de ofrecerlo al público meta.

Es recomendable evaluar desde el participante, los materiales disponibles y el sistema técnico con el objetivo de modificar y mejorar su calidad para una nueva versión. Se recomienda llevar a cabo esta evaluación tanto al inicio del proyecto, como una vez finalizado. Para identificar este proceso de evaluación, se utiliza el término evaluación de los cuerpos colegiados, porque se toma en cuenta la valoración de todo el equipo interdisciplinario y los usuarios del proyecto.

Los proyectos educativos en línea buscan, principalmente, satisfacer una necesidad, adaptarse a nuevas limitantes (tiempo y espacio), abarcar geografías distantes, y ampliar, así, la oferta educativa como el ejemplo descrito, en el que se aprovechan, pedagógicamente, las tecnologías de la información y la comunicación.

\section{CONSIDERACIONES FINALES}

- Una de las estrategias que debe estar presente en todo proyecto educativo es el proceso de la evaluación. Cuando se utilizan recursos tecnológicos, se hace necesario que ésta sea

1 Se utiliza el término interdisciplinario en el ámbito de la integración, pues la visión del profesional involucrado no sólo se nutre de su saber, sino que, también, incorpora la visión disciplinar de los otros, pero articuladas estas visiones por la racionalidad de la escolarización. 
puesta en práctica, en forma paralela al diseño de cualquier proyecto. La evaluación debe contemplar, entre otros aspectos; el rendimiento de los estudiantes en el evento educativo, el costo, el tiempo, la demanda, el impacto social, la evaluación de los materiales y los recursos tecnológicos; con esos se prueba el material audiovisual, el material escrito, el software, entre otros. Es preferible considerar una evaluación tanto cualitativa como cuantitativa, y tomar en cuenta las actitudes, los valores y el impacto sociocultural.

- La educación en línea permite incorporar distintos elementos llamados interactivos en el proceso de aprendizaje: se deben aprovechar los múltiples medios actuales para transmitir mensajes y, por ende, conocimientos de una manera interactiva, para que el usuario interactúe con la imagen, el sonido y el color, de los cuales carecen los medios tradicionales, con una navegación no lineal en la Internet y el uso del hipertexto, para ampliar aquella información que no tenemos.

- Cuando se elabora un proyecto educativo con uso de la tecnología de la comunicación e información, es necesario tomar en cuenta criterios de calidad, relacionados con diferentes aspectos, tales como: los cursos, los contenidos, la evaluación, los relacionados con los actores (estudiantes y docentes) y los relacionados con el ámbito institucional. No debe olvidarse, en el planteamiento y desarrollo de un proyecto, la relación de la educación y el entretenimiento, relación conceptual conocida como edutaiment. Con este planteamiento, el aprendizaje se da "sin darse cuenta", sin ningún esfuerzo. Si existe en el proceso educativo alguna dificultad, ésta es vista como algo interesante, lo cual motiva al usuario a seguir descubriendo y construyendo el aprendizaje.

- $\quad$ El equipo responsable de un proyecto de educación en línea, deberá, al menos, reunir un perfil de competencias, características y actitudes relacionadas con el ser creativo, crítico, comunicador y conciliador; poseer conocimientos y habilidades en el uso de los medios de comunicación a distancia: correos electrónicos, foros de discusión, transferencia de archivos, presentaciones en Power Point, videoconferencias interactivas, entre otros, así como conocimientos didácticos.

- $\quad$ En el desarrollo de un proyecto, es necesario recordar toda la información pertinente al uso de la Internet, las reglamentaciones y los convenios promovidos por la UNESCO, los aspectos relacionados con la protección del derecho de autor y derechos conexos, aplicables para todas aquellas obras artísticas y literarias que se protegen (aunque se encuentren en la Internet). Cada país, y no es la excepción Costa Rica, toma lo necesario de los distintos convenios, de acuerdo con sus legislaciones. Por esto, muchos de los materiales son encontrados con algunas restricciones, sólo por mencionar algunos ejemplos: materiales con claves de acceso, pagos con tarjetas de crédito, formatos PDF y número limitado de copias para su impresión. Estos derechos de la sociedad del conocimiento se derivan de la revolución tecnológica de finales del siglo XX y principios del siglo XXI, aspectos que deben ser tratados por los especialistas en este campo del conocimiento.

- $\quad$ El alcance y la complejidad que requiere la organización académica y administrativa de un proyecto de educación en línea, involucra diversas dependencias de una o varias instituciones, desde la que lo emite hasta a la que va dirigida. Es un proceso dinámico en el cual, seguramente por sus características, surgirán cambios sobre la marcha, pero en lo que sí debemos estar alertas es en aquel aprendizaje que otros hayan desarrollado en el área de la educación en línea, y de aquellos que, con el sólo aventurarse en este campo, nos sorprenden con sus aprendizajes. 
- Un proyecto de educación en línea será exitoso en la medida que exista vinculación entre los objetivos de aprendizaje y los estudiantes, en el que todos los participantes en el proceso educativo, incluidos los asesores y profesores, sean considerados sujetos de aprendizaje.

\section{REFERENCIAS BIBLIOGRÁFICAS}

Angulo, L. (2006). Estrategia y toma de decisiones para la educación a distancia. Revista Educare, Vol. IX, $\mathrm{N}^{\circ} 2,111-121$.

Bates, T. (2001). Cómo gestionar el cambio tecnológico. Estrategias para los responsables de centros universitarios. Resumen ejecutivo y primer capítulo. Barcelona, España: EdiuocGedisa.

Bates, T. (2000). Managing Technological change: strategies for collage and university leaders. San Francisco, United States: Jossey-Bass Publishers.

Miratía O. (2001). Las tecnologías de la información y la comunicación en la educación. Revisando el pasado, observando el presente, imaginándonos el futuro. Universidad Central de Venezuela. Congreso venezolano de Educación e Informática. Valencia.

Otras Fuentes consultadas

Chan, M. \& Pérez, C. (2003). Propuestas metodológicas para le evaluación de la educación en línea. Guadalajara: Universidad de Guadalajara. Coordinación General del Sistema para la Innovación del aprendizaje (INNOVA).

Méndez, J. (2004). Vídeo Conferencia Grupal. Estructura de Comunicación y Diseño Instruccional CUAED-UNAM. Versión electrónica: recuperado el: 11 de octubre, 2005, de http://www. cuaed.unam.mx/puel cursos/proyectos ed/modulo/materiales

Morero, M. (2004). Nuevos rumbos para la educación. Cuando las brechas se vuelven caminos. Guadalajara, México: Universidad de Guadalajara. Coordinación General del Sistema para la Innovación del aprendizaje (INNOVA).

Torres, A. (2004). La educación superior a distancia. Entornos de aprendizaje en red. Guadalajara, México: Universidad de Guadalajara. Coordinación General del Sistema para la Innovación del aprendizaje (INNOVA). 